\title{
Access of the general public to basic life support courses \\ in the Russian Federation: a web-based analysis
}

\section{Alexei Birkun}

Medical Academy named after S. I. Georgievsky of V. I. Vernadsky Crimean Federal University, Simferopol, Russian Federation; e-mail: birkunalexei@gmail.com

Purpose of the study. To investigate the availability and to characterize basic life support (BLS) courses proposed for lay people in Russia.

Materials and methods. In July 2018, Google and Yandex were searched for Russianlanguage web resources offering BLS education for adult laypersons in the form of courses, and descriptive analysis was performed. Eligible on-site training courses were limited to those provided in the territory of the Russian Federation.

Results. A total of 3,200 initial search results yielded 55 unique proposals to get trained in BLS from 43 organizers. The number of courses per 10 million population of the Russian Federation is 3.7. BLS is mainly taught as part of the first aid courses (84\%), whereas BLSfocused courses are less common (16\%).

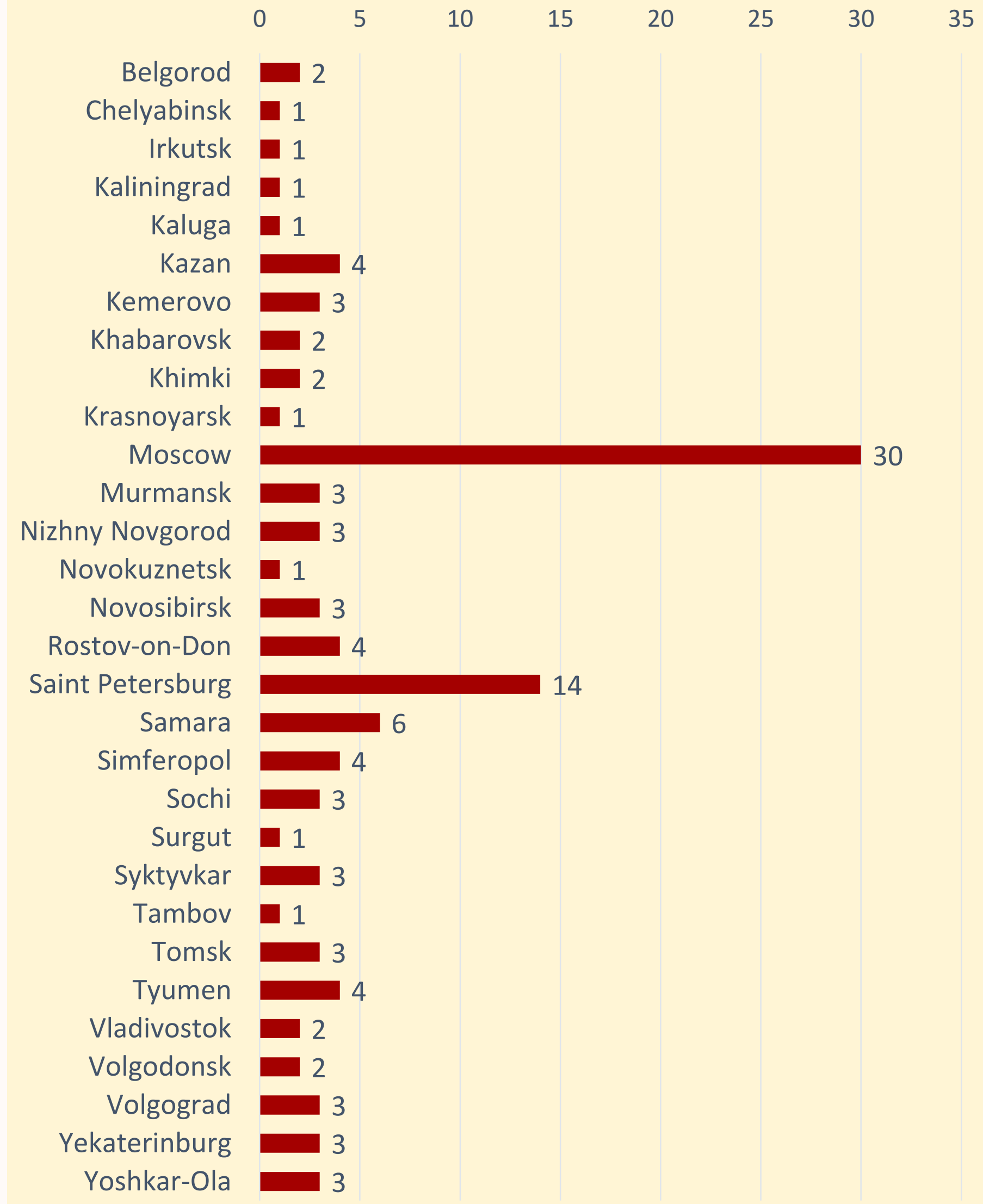

Figure. Distribution of the BLS courses by cities

A syllabus of $22 \%$ courses includes automated external defibrillator use and some kind of assessment of resuscitation knowledge/skills. On-site training is offered by $96 \%$ courses, and two courses (4\%) utilize distance learning. The courses show significant diversity as of instructors' qualifications, duration of training (1-36 hours) and number of trainees per group (4-18 persons). Most courses are paid (95\%; mean cost per trainee is 55 US dollars). Course geography is limited to 30 cities (1.9\% urban settlements of the country; see figure). More than $80 \%$ of on-site courses are provided in Moscow and Saint Petersburg. According to the provided descriptions, $14 \%$ courses are concordant with outdated editions of international resuscitation guidelines.

Conclusions. The availability and accessibility of public resuscitation training in Russia is critically limited. The BLS courses are few, show high organizational and methodological heterogeneity, as well as confined and uneven geographical distribution. There is an acute need to increase access of the country's population to high-quality resuscitation training. Use of alternative teaching methods, including blended learning, may help to improve the situation in a cost-effective way. 